\title{
The glucagon test in obstructive and hepatocellular jaundice
}

DAVID A. BERSTOCK

F.R.C.S.

\author{
JOHN R. WOOD \\ B.S.c., M.B. B.S.
}

\author{
ROGER WILLIAMS \\ M.D., F.R.C.P. \\ Department of Surgery and Liver Unit, King's College Hospital and Medical School, London SE5 8RX
}

\begin{abstract}
Summary
The plasma glucose response to an intravenous bolus of glucagon was examined in patients with obstructive jaundice, hepatocellular jaundice and in healthy volunteers. Plasma glucose levels were determined before and at 15, 30 and $45 \mathrm{~min}$ after glucagon. The glucose response to glucagon differed markedly in the two patient groups with significantly higher plasma glucose values in the obstructive jaundice group.

Measurement of blood glucose after intravenous glucagon provides a simple test to assist in the differential diagnosis of obstructive and hepatocellular jaundice.
\end{abstract}

\section{Introduction}

Intravenous administration of glucagon to normal man is known to increase plasma concentrations of glucose, adenosine 3'5'-cyclic monophosphate (cyclic AMP) and insulin. Glucagon acts to stimulate adenylate cyclase in liver cells resulting in glycogenolysis and gluconeogenesis (Francavilla, Jones and Starzl, 1978). Van Itallie and Bentley (1955) infused glucagon into normal subjects and cirrhotic patients in the presence and absence of subcutaneously administered adrenaline and suggested that glucagon-adrenaline induced hyperglycaemia may be of value as an index of liver function. Patients with acute viral hepatitis and healthy subjects also showed a marked difference in their plasma glucose response to intravenous glucagon (Felig et al., 1970).

Verhaegen and colleagues (1971) reported on the use of a 'double glucagon test', involving two intravenous doses of glucagon, in the differential diagnosis of liver cell impairment and hepatic obstruction. The present study examines the blood glucose response to a single intravenous bolus injec-

Correspondence to Dr John R. Wood, Department of Surgery, King's College Hospital, Medical School, London SE5 8RX. tion of glucagon in patients with confirmed hepatocellular and obstructive jaundice and also in healthy volunteers.

\section{Patients and methods}

Informed consent was obtained from all patients and volunteers. The glucagon test was performed in 39 unselected jaundiced patients and 21 healthy volunteers. Only subjects eating normally and without diabetes mellitus were studied. The diagnosis of hepatocellular jaundice (alcoholic cirrhosis, primary biliary cirrhosis, chronic active hepatitis, hepatitis B, paracetamol overdose and hepatic secondary deposits) in 21 patients and obstructive jaundice in 18 patients was confirmed in all cases by either liver biopsy or by findings at laparotomy. Five of the patients in the obstructive group had carcinoma of the pancreas and 13 had gallstones, 6 of whom had symptoms suggesting cholangitis.

All subjects were starved overnight for a minimum of $8 \mathrm{hr}$. Patients having intravenous fluids were given only saline during this period. Venous blood samples were taken for estimation of fasting plasma glucose prior to a bolus injection of glucagon (Eli Lilly, 0.025 $\mathrm{mg} / \mathrm{kg}$ body weight). Further blood samples were taken 15,30 , and $45 \mathrm{~min}$ after glucagon injection for plasma glucose estimation.

\section{Results}

Figure 1 shows the plasma glucose response over $45 \mathrm{~min}$ to glucagon injection in patients with obstructive and hepatocellular jaundice and in healthy volunteers. Basal plasma glucose concentrations in obstructive jaundice (mean $5.6 \pm 0.2$ (s.e.mean) $\mathrm{mmol} / \mathrm{litre})$ were significantly higher $(P<0.005)$ than those in the hepatocellular $(3.9 \pm 0.2 \mathrm{mmol} /$ litre $)$ or normal $(4 \cdot 3 \pm 0 \cdot 1 \mathrm{mmol} / \mathrm{litre})$ groups. The rise in plasma glucose after glucagon was more marked in 
obstructive than in hepatocellular jaundice. The difference between the two patient groups was highly significant $(P<0.0005)$ at $15 \min (6.7 \pm 0.3 v .4 .8 \pm 0.2$ $\mathrm{mmol} /$ litre), $30 \mathrm{~min}(7 \cdot 7 \pm 0.3$ v. $5 \cdot 2 \pm 0.2)$ and $45 \mathrm{~min}$ $(7 \cdot 9 \pm 0 \cdot 4$ v. $5 \cdot 0 \pm 0 \cdot 2)$. The two groups were best differentiated at $45 \mathrm{~min}$ where only patients with obstructive jaundice (78\% of the obstructive group) had plasma glucose levels greater than $7.0 \mathrm{mmol} /$ litre. Mean plasma glucose concentrations in normal subjects were $6 \cdot 3 \pm 0 \cdot 1,6 \cdot 2 \pm 0 \cdot 2$ and $4 \cdot 8 \pm 0.2 \mathrm{mmol} /$ litre at 15,30 and $45 \mathrm{~min}$ respectively. The glucose response to glucagon in 5 patients with pancreatic carcinoma did not differ significantly from the response in the 13 patients with gallstones.

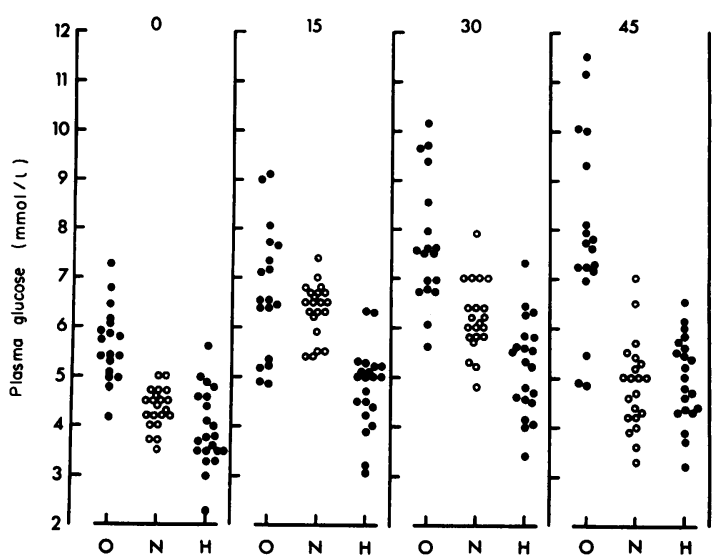

FIG. 1. Plasma glucose concentration in patients with obstructive jaundice $(\mathrm{O})$, hepatocellular jaundice $(\mathrm{H})$ and normal volunteers $(\mathrm{N})$ before and at 15, 30 and $45 \mathrm{~min}$ after glucagon injection.

\section{Discussion}

Previous studies have raised the potential value of a glucagon test as a measure of liver function. These tests have involved either continuous infusions of glucagon (Felig et al., 1970; Francavilla et al., 1978) or repeated bolus doses (Van Itallie and Bentley, 1955) whereas the present test involves only a single bolus injection of glucagon.

Although the differentiation of jaundice into obstructive or hepatocellular on the basis of clinical examination and routine biochemical tests is straightforward in the majority of cases, in a small proportion of cases, more complicated and invasive investigations are required in order to assign them to one or other group. Before tests such as percutaneous cholangiography, endoscopic retrograde cholangiopancreatography (ERCP) or liver biopsy are performed it may be of value to have further evidence to support one or other diagnosis. This could be provided by the glucagon test.

The above measurements show that the blood glucose at $45 \mathrm{~min}$ after glucagon injection was the best single discriminant in separating the two jaundiced groups. Only those patients with obstructive jaundice showed an appreciable rise in blood glucose, whereas those with hepatocellular jaundice tended to have a flat glucose response.

The low levels of fasting glucose found in a large proportion of the hepatocellular group have been observed previously in patients with viral hepatitis (Felig et al., 1970). The underlying mechanisms involved in the differing response of jaundiced patients to glucagon are likely to be complex resulting from differences in hepatic glycogen content, insulin and glucose metabolism and other factors affecting carbohydrate metabolism. It is of some interest that patients with longstanding obstruction showed a marked rise in blood sugar after glucagon, whilst two patients who had very mild hepatitis clinically with little or no constitutional upset, nor any marked biochemical abnormality other than a raised bilirubin, had very flat glucose response curves to glucagon. These cases serve to emphasize the possible value of the above test which when used in conjunction with other biochemical investigations may increase the accuracy of diagnosis in jaundice.

\section{References}

Felig, P., Brown, W.V., Levine, R.A. \& Klatskin, G. (1970) Glucose homeostasis in viral hepatitis. New England Journal of Medicine, 283, 1436.

FranCavilla, A., Jones, A.F. \& STARzL, T.D. (1978) Cyclic AMP metabolism and adenylate cyclase concentration in patients with advanced hepatic cirrhosis. Gastroenterology, 75, 1026.

VAN ITALlie, T.B. \& BENTLEY, W.B.A. (1955) Glucagon induced hyperglycemia as an index of liver function. Journal of Clinical Investigation, 34, 1730.

Verhaegen, H., De Beukelaer, A., Verhaegen-DeClercQ, M.L. \& KRUG, F. (1971) The double glucagon test, a new liver function test. Postgraduate Medical Journal, 47, 108. 